\title{
Cognition, emphasis, and the viewer's experience of fine art
}

Katie McCallum

University of Brighton
Scott Mitchell

University of Brighton
Thom Scott-Philips Central European University

Durham University 
Hushed Tones 2

\section{Abstract}

Art theory has consistently emphasised the importance of situational, cultural, institutional and historical factors in viewers' experience of fine art. However, the link between this heavily context-dependent interpretation and the workings of the mind is often left unexamined. Drawing on recent developments in cognitive pragmatics, we here argue that fine art achieves its effects by prompting the use of cognitive processes that are more commonly employed in the interpretation of words and other stimuli presented in a communicative context, drawing an analogy between gallery framing and communicative emphasis. More generally, we situate and describe the Western fine art tradition as a phenomenon that is a consequence of both human biological heritage-in particular the cognitive processes involved in communication—and of cultural norms, practices and institutions. 


\section{Hushed Tones 3}

\section{Introduction}

When confronted by a piece of art, we often entertain rich, surprising and complex thoughts, and this process often feels consistent across otherwise very different prompting phenomena. Our goal here is to use insights from cognitive pragmatics and the philosophy of language to describe art interpretation in natural scientific terms. We focus in particular on the contemporary Western fine art tradition, but we believe that our observations and arguments will apply more generally. To be clear, we are not offering an account of creativity; nor do we make any suggestions about the way that the art world should be, or how art should be interpreted. Nor are we focused on the relationship between aesthetics and factors of individual difference, such as personality and emotion. We are concerned instead with how the viewer's experience of fine art functions from a cognitive point of view. The topic is particularly pertinent in a time when fine art has become remarkably diverse, with few if any consistent features in appearance or medium.

In particular, we draw an analogy between the effects of the modern fine art gallery on an art viewer, and the effects of emphasised utterance on a hearer, conveyed, for instance, by means such as unusual prosodic patterns, repetition and use of linguistic intensifiers. The kinds of interpretations entertained when contemplating art can of course be very different to those reached during the live process of a conversation-but, we suggest, the underlying cognitive processes used in ordinary human communication also come into play when contemplating art. We argue that when an object is displayed in a modern fine art gallery, by the intentional choice of an artist in combination with the evident approval of the artworld institution in which the gallery operates, this provides a viewer with evidence of particular kinds of intentionality. This evidence, like an added emphasis, provides motivation to seek out effortful interpretations, which may in consequence be rich and varied. In addition, the art-world framing legitimates a viewer's entertaining multiple, speculative interpretations without resolving them. In such ways the highly artificial gallery setting prompts a reverential way of approaching art.

In $\ 2$ we describe human communication as a diverse family of different means by which we express and recognise intentions, and we highlight the compatibility of this approach with current thought in art theory. In $\$ 3$ we describe, in cognitive terms, how emphasis can encourage an audience to search for interpretations beyond those that they otherwise would, and we argue that art institutions effectively facilitate this 
process. In $₫ 4$ we describe the skill that contemporary artists must have to produce artworks able to reward this additional search for worthwhile cognitive effects, and in $\$ 5$ we explain many of the common features of audiences' experiences of interpreting and otherwise engaging with art in modern, white-cube galleries. We take as our starting point Relevance Theory, a cognitive account of human communication that has, over the past 30 or so years, been developed, defended and tested at length (see $₫ 2$, below). Our goal is to use these findings to explain, in cognitive terms, many of the most distinctive features of the fine art world, as observed and described by art theorists. In so doing, we build new bridges between the cognitive sciences, on the one hand, and the humanities on the other. Throughout we illustrate our key points with reference to specific works of art, by artists such as Marcel Duchamp, Mark Rothko, Ai Weiwei, and others.

\section{Interpretation in the round}

Following most cognitivist approaches to communication, we do not view non-linguistic means of communication—raised eyebrows, grunts, pointing and so on—as somehow derivative or impoverished relative to language (McNeil, 2005; Kendon, 2004; Scott-Phillips, 2014; Wharton, 2009; Wharton, 2016; Brabanter, 2010). Rather, we turn that picture on its head, seeing human communication as a family of different means of expression, all of which are inherently contextual and underdetermined, albeit to different degrees in each case. Linguistic communication is, of course, a crucially important member of that family, but it is best seen as a special case, one that makes use of structured collections of culturally evolved tools (words, grammars) that typically function to make communication more exact and less underdetermined than it otherwise would be (Sperber \& Wilson, 1995; Sperber \& Wilson, 2015; Wharton, 2009; Scott-Phillips, 2014; Carston, 2002).

This view of communication aligns closely with the skepticism among many art theorists towards any attempt to identify art with communication in any simple sense; as Theodor Adorno observes, “...the contemporary situation of art is hostile to what the jargon of authenticity calls the 'message"' (Adorno, 1997 p. 32) Adorno himself desired to push away from such an understanding and toward a complex and unresolved picture of interpretation, stating that art ought to "set thought processes in motion, not to communicate maxims" (Adorno, 1997 p. 32). It is just these kinds of active mental processes that cognitive pragmatics—and Relevance Theory in particular—recognises and attempts to account for. The 
transmission of a definite message, or simple retrieval of a speaker's meaning, is for such theories not necessarily the (or even a) outcome of communicative acts. Instead, communication is an activity of overtly raising, in one way or another, the psychological salience (manifestness) of various beliefs, ideas, and other mental states in an audience. This approach allows for a subtle spectrum of conscious and unconscious effects in communication (see in particular Sperber \& Wilson, 2015).

Thus, we certainly do not claim that art can be 'decoded' in any traditional sense of the word (we do not even believe that ordinary linguistic communication is a matter of decoding alone). Nor do we claim that viewing an artwork is a mirror process to engaging in a conversation. What we do claim is that some cognitive processes are shared across various forms of interpretation, and consequently that it will be fruitful and insightful to compare interpretation in ordinary conversation, with interpretation of art. It has previously been argued that this approach could be used to analyse literature, with the goal “...not to produce better interpretations than actual hearers or readers do, but to explain how they arrive at the interpretations they do construct, whether successfully or unsuccessfully" (Wilson, 2011: 4). What we are proposing is that a similar project can be pursued with respect to fine art and is likely to be a valuable source of insight and understanding.

Another way to make these points is to say that the openness of interpretation that clearly exists in the case of art is not a departure from everyday interpretation more generally, it is simply (much) more openended. Ordinary linguistic utterances underdetermine their meaning, often vastly so (Grice, 1989 p.31; Recanati, 2001; Sperber \& Wilson, 1995 pp.181-182; Carston, 2008). They are, quite typically, multiply ambiguous, and often contain expressions that do not specify their referent at all (e.g. it, she, this, that, to highlight just the most obvious and ubiquitous cases). In consequence, interpretation in context is always necessary. The distinction between interpretation in everyday conversation and the interpretation of art is, therefore, a distinction not between encoded messages and something qualitatively distinct from that, but rather a graded distinction between two subunits in the larger family of human communication.

The key theoretical notion that unifies these different means of human communication is ostension. Ostension is, in essence, the overt expression of intentionality. By being overt, ostensive acts give "two layers of information" (Sperber and Wilson, 1995: 50); they point out some piece of information, and they point out that this pointing out was done deliberately, for the audience's benefit. Consider, say, a park bench 
with two people, Mary and Peter, sat eating ice cream (Sperber and Wilson, 1995: 48-49). Peter leans back and so alters Mary's field of view to include an ice-cream vendor, a stranger and their mutual acquaintance Bill (whom they both dislike). This makes a variety of conclusions available to Mary, most immediately and most obviously that Bill is here, in the park. Note however that Peter might lean back in one of two ways. He might do so in a casual fashion, not revealing to Mary that he has leaned back in order that she sees Bill; or he might do so in a more overt, stylised way, thereby bringing attention not only to Bill, but also to the fact that he (Peter) has leant back so that Mary can see Bill. This makes available to Mary not only the fact that Bill is in the park, but further facts too, in particular that Peter has noticed Bill, that Peter intends for Mary to see that Bill is in the part, and various other possible conclusions that might follow from this. Ostension is the word given to describe this deliberately overt behaviour.

In another example, a woman is travelling in a foreign country and exits her hotel in some light, summery clothes (Sperber and Wilson 1995: 51-52). As she walks, she makes eye contact with an old man who looks slowly up towards the sky, which draws her attention to some small clouds. On her first look, these clouds were not of any relevance to her perception of the day as a beautiful one. Now, however, because the old man has drawn her attention to them, the clouds open up a range of inferences previously unconsidered. Moreover, these new inferences must be relevant to her, or else why would the old man have performed the ostensive act? The inference that the weather will turn cold and wet is not only made more accessible to her, but is in fact the most probable reason for his engaging in communication.

Ostension, then, is behaviour that not only makes something deliberately salient, but does so in such a way that it provides an implicit guarantee that interpreting the stimulus is worth the effort required and should produce worthwhile cognitive effects. This insight, known as the Communicative Principle of Relevance, is more exactly stated as "[e]very ostensive stimulus conveys a presumption of its own optimal relevance" (Sperber and Wilson 2004, p.612). In consequence, if artwork encountered in a gallery is perceived as an intentionally made for the purpose of being interpreted (i.e. if it is perceived as ostensive), then the viewer's experience of that object will be formed with some reference to that intentionality (Scott-Phillips, 2015). This is a sympathetic and fruitful description of art, much more so than any simple picture of communication based upon the encoding and decoding of explicit messages. 
Intentionality has long been an important topic in art theory. Roland Barthes' Death of the Author, for example, famously shifted the focus away from the author and onto the relationship of audience and text (Barthes, 1978), a move partially anticipated by Wimsatt and Beardsley (1946) and the New Criticism school. Subsequent analyses of the role of intention in fine art often include some response to Barthes (e.g. Fodor, 2012; Farrell, 2017). In the philosophy of mind, Jerry Fodor effectively argued that art is ostensive (even though he does not use that word), stating that "artworks are intended to affect audiences in certain ways, and to do so partly in consequence of the audience's recognition of this intention" (Fodor, 2012 p.62). The production of art is seen, in consequence, as the making of "interpretable artifacts" (Fodor, 2012 pp.66-7). What we are pointing out is that, from a cognitive point of view, more ordinary communicative stimuli, such as words, are also "interpretable artifacts", and that the substantive differences between words and artworks are differences of degree: one class of objects is (typically) more open-ended than the other. We also emphasise the role of framing, which is the means by which intentions are made overt (ostensive) (see also \$3). But agreeing with Fodor and Barthes, we do not claim that artists do or should have clear, conscious intentions about specific content. In fact, it is clear that an artist's intentions are complex and multiple. Nor do we expect viewers to retrieve a particular, unvaried and predictable interpretation. The suggestion is, rather, that audiences react to art, in art galleries, as they react to other ostensively presented stimuli. In other words, the artworks are perceived as intentional (whether or not they are), and audiences take this into account in the interpretive process. As we shall elaborate in the next section, this interpretative process involves the investment of some degree of cognitive effort, and can result in complex conclusions that are speculative and unverifiable.

We emphasise in particular the role played in this process by galleries, which can provide an artwork with a degree of institutional backing. It is certainly clear that placing an object in such a setting as artificial as a modern white cube gallery is an act that places great emphasis on that object. This acts not only as evidence of the art-world's sanctioning, but also increases the level of ceremony with which an object is treated. In fact, an artist's declared intentions are not enough on their own to prompt the kind of treatment that we are focusing on; when submitted under the name 'R. Mutt,' Duchamp's urinal (1917; Figure 1) ${ }^{1}$ was initially rejected outright despite the exhibition's original promise to display every work of art that

\footnotetext{
${ }^{1}$ Now thought in fact to have been the work of Baroness Elsa von Freytag-Loringhoven (Higgs, 2015)
} 
was submitted, and only after Duchamp's famous name was brought into play—a clear signal of art-world approval—was it considered and discussed in the way that it is now (Higgs, 2015). More generally, while our discussion is focused on the role of galleries, our points here apply across the full spectrum of artworld framing, from the affixing of a well-known name, to the displaying of physical cues such as name tags. All are means of expressing overt intentionality.

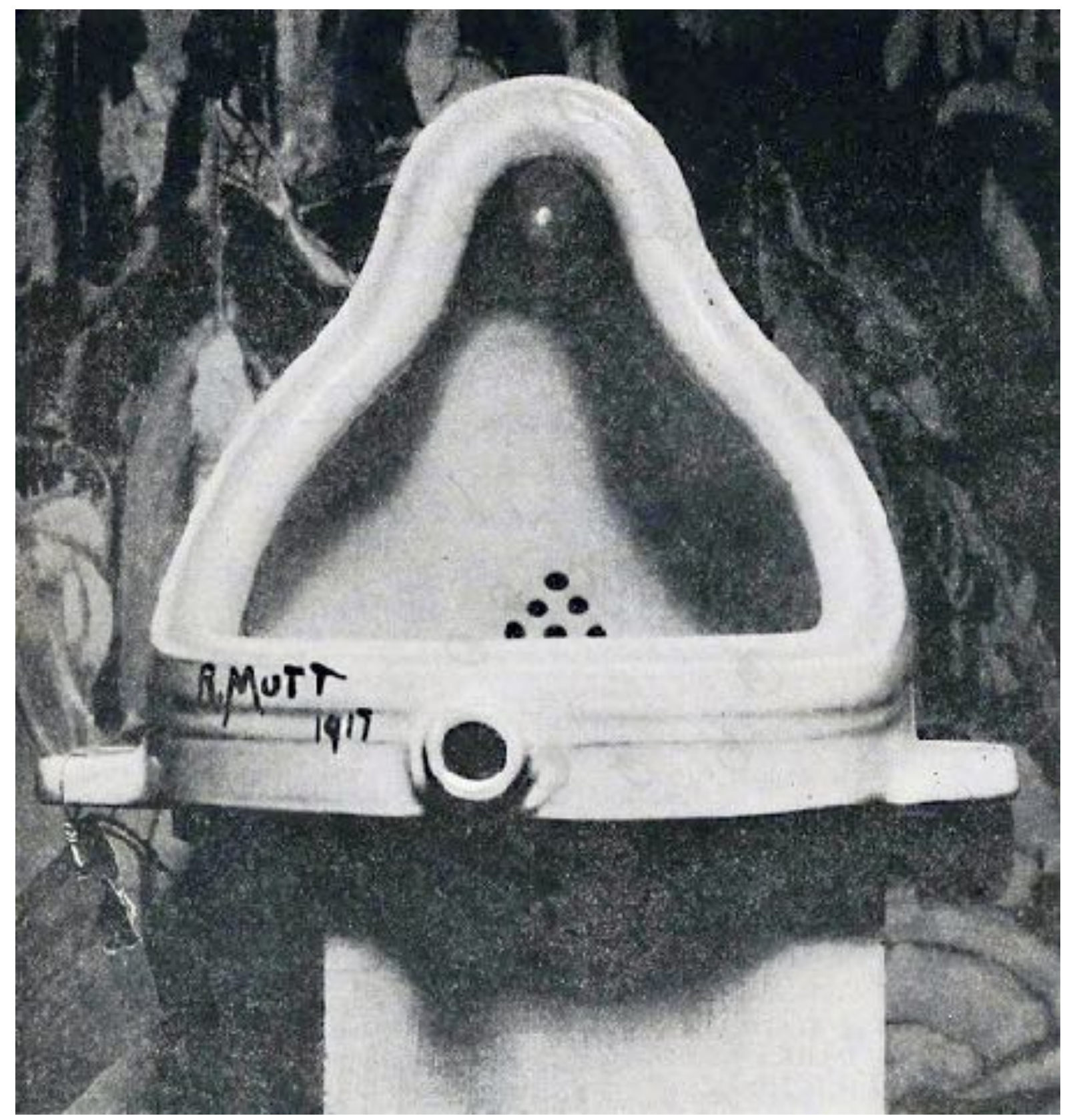

Figure 1: Fountain, Marcel Duchamp (1917). This work was initially rejected from a gallery show, and only accepted as a work of art after Duchamp's famous name was brought in to play. Image from Wikimedia Commons.

The communicative account that we are putting forward here links closely with ideas from the world of art theory. Our approach could be read as an account of how an Institutional Theory of Art, such as that 
put forward by Arthur Danto (1964), might work in cognitive terms. Institutional theories of art suggest that what decides that art is art is its recognition as such by empowered institutions, or the extent to which it displays signals that refer to that institutional structure. "To see something as art requires something the eye cannot descry—an atmosphere of artistic theory, a knowledge of the history of art: an artworld."(Danto, 1964)—reformulated later by George Dickie, "A work of art in the classificatory sense is 1) an artifact 2) on which some person or persons acting on behalf of a certain social institution (the artworld) has conferred the status of candidate for appreciation," (Dickie, 1971: 101, italics added). Jerrold Levinson's “historical account" (1979; 1989) makes similar proposals, albeit with greater emphasis on how artworks reference an artistic canon, rather than their promotion by an institution (see also Bullot \& Reber, 2013). What we propose is that the institutional framing that these accounts emphasise actually motivates viewers to have a richer and deeper experience which might not be achieved otherwise, exactly because the artwork has been presented, in Dickie's words, as a "candidate for appreciation". The quiet space encourages careful contemplation while exerting the institution's power.

\section{Emphasis and cognitive effects}

As mentioned, we situate our work in the relevance-theoretic understanding of cognition and communication, according to which the interpretation of stimuli perceived as ostensive (i.e. as being overtly for the audience) is guided by heuristic estimates about the signallers' intentions and the anticipated quantity and quality of the cognitive effects that might be achieved (Sperber \& Wilson, 1995; Carston, 2002; Wilson \& Sperber, 2012; Clark, 2013). These estimates in turn guide how much cognitive effort is invested in interpretation (i.e. if the hearer thinks a speaker is uninteresting, the effort put in will be reduced). Cognitive effects include, for instance, strengthening or contradicting an existing belief, such that new information follows; and factors that can affect cognitive effort include, for instance, perceptual salience, ease of retrieval from memory, linguistic or logical complexity, and so on. Relevance is the trade-off between these two factors, effects and effort (Wilson \& Sperber, 1986; Sperber \& Wilson, 1995; Wilson \& Sperber, 2005).

Emphasis is a topic of current study within this literature, and indeed in linguistics more generally (Werth, 2016; Jackson, 2016; Scott \& Jackson, 2017). When emphasis of some form is added to a sentence or utterance, it effectively tells the hearer to invest more effort in finding interpretations: "emphasis [...] 
suggests to the audience that there are suitable effects on offer, and that substantial effort should be invested in 'digging deep' to recover these effects" (Jackson, 2016: 273). Jackson further suggests, echoing our proposals here, that emphasis is a family of behaviours which show to various degrees that additional effort investiture should take place and that additional effects are available.

Consider, for instance, this pair of contrasting linguistic utterances:

\author{
Miss X sang 'Home sweet home' \\ Miss X produced a series of sounds that correspond closely with the score of 'Home sweet home'
}

This is a famous example in the philosophy of language. Paul Grice, who first presented it, glosses the interpretative process as follows: "Why has he selected that rigmarole in place of the concise and nearly synonymous sang? Presumably to indicate some striking difference between Miss X's performance and those to which the word singing is usually applied. The most obvious supposition is that Miss X's performance suffered from some hideous defect. The reviewer knows that this supposition is what is likely to spring to mind, so that that is what he is implicating" (Grice, 1975: 56). This example nicely (and somewhat dramatically) illustrates not only that everyday communication is guided by presumptions of relevance, but also how emphasis— which in this case takes the form of an overtly opaque formulationcan direct an audience towards an interpretation richer than would be derived from a more 'literal' reading.

Similar effects have been previously discussed with regard to the writings of intellectual gurus, where opaque formulations prompt (some) audiences to search for additional cognitive effects (Sperber, 2010). What we are suggesting is gallery framing is a part of the wider collection of emphatic behaviours, the function of which is to suggest to the audience that increased investment of cognitive effort is likely to lead to greater cognitive effects. Gallery framing, we argue, allows for and provides motivation for the production of interpretations that are more effortful—more complex, weightier and less functional—and so less likely to be reached than without that framing. To be clear, we are not suggesting that artists and galleries are deliberately obscurantist in the way that intellectual gurus are sometimes accused of being. We are, rather, simply suggesting that similar cognitive processes of interpretation apply in each case, and indeed in many other cases too. 
Artists are skilled at making "interpretable artifacts", as Fodor suggested (see above), and artists do this in an open and explicit way. In other words, constructing artefacts that elicit and accommodate multiple, complex interpretations in the mind of a hardworking creative viewer simply is what many artists do. Furthermore, within a typical gallery setting, artists are not present to engage in the feedback processes that are present in a conversational exchange and so cannot highlight, clarify and specify their intentions. (And besides, artists may not be consciously aware of their intentions) The only stimulus available is the art and the way that it is presented. In addition, the type of intentionality expected in the art world, reinforced by institutional modes of discourse, is multiple and unresolvable. This all opens the field of interpretation in interesting ways. The viewer's expectations of relevance are free to be satisfied by interpretations that are contingent, speculative, and often personal, so long as sufficient positive effects are found. (We discuss under what circumstances an artwork might leave a viewer unsatisfied in $₫ 4$, below.)

As such, the viewer of fine art is, in a sense, in a position of power over the artist: over what aspects of the stimulus (and its environment) will be taken account of in producing interpretations, and hence over whether to accept or deny any particular interpretations. This is a shift in the location of authority when it comes to identifying a 'correct' interpretation from where it might be expected to be in the case of more ordinary cases of human communication i.e. with the speaker. Authority does not rest with the artist to the same extent that it rests with the speaker of an ordinary utterance, and in this way viewers of fine art can have interpretations that cannot definitively be said to be wrong. Note, moreover, that some of the features of languages that make them particularly suitable for the expression of exact and specific intentions - in particular systematic syntactic structure and conventions of meaning (semantics)—are generally absent in art. This is one clear difference with the words of intellectual gurus which, being words, are generally expected to be clear and moderately exact (even if they are sometimes not). Art, in contrast, gives specific reason and motivation for a viewer to entertain multiple possible interpretations simultaneously.

These effects are, in turn, magnified by a gallery framing. Coupled with the shift in authority discussed above, they impact on the very purpose of art for both viewers and artists. As art exists primarily for the expression of ineffable, revelatory and/or non-propositional mental states, the communicative force of an artwork is to be found in its capacity to create these forms of experience in the mind of the viewer, 
rather than the more definitive, clarificatory work of that is typical of linguistic conversation (not to mention other ordinary means of human communication).

In fact, in some contexts individual or institutional authority can reinforce attributions of profundity. In such ways a 'hushed tones' environment can sustain itself (and indeed become institutional in the first place). Individuals sometimes offer public interpretations or endorsements of an artefact, or a text, whose value may otherwise be opaque or unclear. Organisations_-such as a white-cube gallery, a religious group, or an intellectual school—can do this too, sometimes simply by displaying or otherwise highlighting the object in question. In doing so individuals and organisations vouch not only for the value of that object, but also for their own authority and reputation (not to mention that of the object's creator). The importance and value of the work is thus made a public indicator of the competence and reliability of the interpreter. Moreover, since the importance of the object is based in part on the creator's reputation as someone competent and reliable, the interpreter's reputation can become intertwined with this also. "The greater this [work's] value and this [author's] authority, the more [the interpreter is] justified in joining the process, and the less the tentative and partial character of their interpretations can be seen as a negative reflection on their own intellectual abilities" (Sperber, 2010 p.591). This gives communities engaging in this collective endeavour reason to invest in reputation-protecting mental spaces that allow for multiple, speculative, tentative or partial interpretations. This effect spans a range of cultural domains, such as the writings of intellectual gurus, the advancement of science, religious texts and artefacts, artworks as presented in modern white-cube galleries, and many others too.

\section{Skill and framing}

In the older western tradition, artworks brought with them their own arguments for value, and earned a place in society accordingly. Artists would do considerable skilled technical work to make one thing look like another. The artwork's value is largely self-evident, from the price and difficulty of the materials to the skill and time of the artist. At this time the artwork was procured by wealthy patrons and often served as a status symbol. The inference that someone must be very wealthy to afford to have these objects is available without bringing intentions into play. (There is of course some ostensive element to the displaying of wealth through such objects.) However, respect for artworks often goes beyond the self-evidence of wealth. In Vogel's Net: Traps as Artworks and Artworks as Traps, Alfred Gell discusses how respect for 
making can shift into a sort of spiritual appreciation. He discusses an eel trap being more carefully and intricately made than it needs to be, and thus appearing to have spiritual connotations (Gell, 1996). Displays of spirituality and displays of wealth went hand-in-hand during the Renaissance, when wealthy individuals_ - or groups of individuals—-would publicly pay large sums to adorn and decorate churches with religious imagery. In all such instances, the effort and skill required to make such artworks was evidence for the devotion and commitment of both artist and commissioner.

As these art objects have shifted in their public availability and modes of presentation, viewers have been faced with an interesting decoupling. A portrait, when placed in a gallery rather than a drawing-room, does not serve the social purpose it once did, but the labour is still evident, and it is valued as a thing-initself. There has thus been an increasing tendency to focus on the intentions of the artist, which are brought far more into the fore with the decline of commissioned portraiture and the increased emphasis on free expression. Increasingly, alongside discussions of the artist's skill and artwork's beauty, viewers discuss at length the conceptual, political or narrative advances made in pieces and oeuvres. Rather than understanding a work as primarily displaying the wealth of the patron or a spiritual significance, we engage with why an artist has chosen this style, these materials, this subject matter. In short, rather than thinking about what a work of art displays, we now discuss what it says.

This shift, from displaying to saying, mirrors a classic distinction in pragmatics and the philosophy of language between showing and meaning, as different ways by which communicators might provide evidence of their intentions (e.g. Grice, 1957; Searle, 1969; Sperber \& Wilson, 2015). Cognitive approaches have long emphasised that this distinction is a graded one, with many intermediate points (Sperber \& Wilson, 2015). Numerous art theorists have noted this distinction between showing and meaning in, for instance, the way that traditionally 'men's arts' such as painting and sculpture are treated, as compared with traditionally 'women's arts' such as quilting and embroidery (e.g. Garber, 1992; Collins \& Sandell, 1987; Parker, 2010). Confronted with a beautiful depiction of a vase of lilies embroidered on a bedspread, a viewer would be likely to appreciate the skill involved in its creation. However, on encountering a depiction of a vase of lilies in a painting, a viewer would be more likely to entertain interpretations such as that the artist 
was contemplating death and mortality, which do not seem to be so available in the bedspread case. ${ }^{2} \mathrm{An}$ embroidered vase might be seen as showing lilies, whereas the painting of the same would be treated as meaning lilies.

In consequence of this shift from displaying to saying (showing to meaning) within the Western art tradition, many modern artworks are known as artworks despite not displaying their labour intensiveness on their sleeves; and, conversely, evidence of a maker's skill is by itself not a sufficient condition for considering it art. Nowadays, the skill of the artist as craftsperson is less evident; and disparaging comments such as 'my five-year-old could do this' produced by less cooperative viewers are commonplace, even clichéd. It becomes very evident in the case of a work like, say, Bottle Rack by Marcel Duchamp (1914)— literally just a spiky metal rack used for the drying of bottles—-that meanings are not inherent in the object, but are teased out by the viewer when considering why the artist has placed this thing in this place in this way. For the bottle rack, a practical reading like 'it's been hung up to dry' will seem likely in a home setting, but not in a gallery. Similarly, Ai Weiwei’s Dropping a Han Dynasty Urn (1995) is typically read in terms of its cultural and political import, as a comment on the rupture between past and present (even if some viewers opt to instead view it as vandalism, and to criticise it on those grounds).

In sum, what we are suggesting is that artworks are, in the contemporary art world, subject to a framing effect that prompts intention-based interpretive work that, while making use of the same or similar cognitive mechanisms that are involved in more ordinary cases of communication, goes significantly beyond that expected and conducted in everyday life. The gallery setting gives the viewer motivation to do extra work to seek out 'arty' consequences, and speculatively entertain them as intentional. It also provides a context. Part of the great skill attributed to Duchamp is his knowledgeable comments on and rebellion against the western art tradition. Both Duchamp's comment, and his capacity to implicate such a comment, are dependent on the sort of context that is made manifest by being in a gallery.

\footnotetext{
2 These arts have now been broadly taken up in particular by artists engaging with feminism, including Tracy Emin, who consciously comments on this divide by engaging with that medium as 'the art of the personal.' (Parker, 2010: $\mathrm{xv})$
} 
This speculative entertaining process depends, of course, on the viewer's willingness to engage with it and invest effort in it. Take, for example, this quote from Andrew Graham-Dixon, in episode three of his BBC4 series 'The Art of France':

"I think he was trying to get rid of the idea of the artist as creator. He said he wanted to destroy the notion of the artist as hero. From now on, the artist would just be someone who chooses a thing and places it in the world. He said that the object should be ordinary because if I chose something, he said, if I chose something that I liked, well then my taste would enter in, and once taste enters in, well, art becomes bourgeois again, taste is the enemy of A. R. T.

"But I think Duchamp's being a little bit disingenuous, and I do think that the things he chose, this thing in particular, were... barbed, meaningful, significant. Duchamp was fascinated by the idea that man is prisoner of his sexual impulses. Could this be Duchamp's way of suggesting that everyone alive - every man, at least - is caught in a state of priapic longing, forever suspended, waiting for the moment of sexual conjuction with the female bottle?" (Graham-Dixon, 2017, emphasis in original)

In this clip, Graham-Dixon starts out saying that Duchamp didn't want this to be about his "taste" or intentions, and then speculates confidently about those intentions! The very displaying of an object in an art-world setting immediately overrides the statements of the artist. Placement in a gallery provides evidence of intentionality that overrides the content of statements, just as saying, say, "I don't want you to hear me saying this" would not be taken at face value. The choice of an object is intentional and the placement of that object in the gallery promotes the investigation of that choice that Graham-Dixon undertakes.

\section{The experience of art}

Importantly, the framing effects we have described mean that the viewer often produces genuinely more profound, intense experiences and ideas out of such works than they otherwise would. The work of the artist is in the decisions and the framing, in providing something that will have rewards to offer for your 
contemplative effort, and which will not curtail your contemplative work by putting forward a single, 'correct' answer.

For example, The Rothko Chapel (a non-denominational chapel in Houston, Texas) contains paintings of subtly different hues of, essentially, black. In this case, the gallery's 'hushed tones' are dramatically underlined; the chapel is a quiet space that provides a significant setting. In this silent, impressive room, viewers are presented with a means of contemplating a set of coloured canvases. These hues are ones that they will have seen in the world before, but in the intensity of the 'chapel', viewers describe profound experiences of these colours. In this case it is particularly noticeable that these are not interpretations in the sense of a message, but in the sense of making something more manifest to the viewer. As we mentioned earlier, Relevance Theory and other cognitive approaches to pragmatics take these possible experiences not to be the retrieval of a message, but to be a whole spectrum of conscious and unconscious effects.

For another example, consider Martin Creed's The Lights Going On and Off (2000). It takes a very simple form: there is a room, and in it a light simply switches on, and then a little while later, switches off. Such simplicity keeps processing effort to a minimum. At the same time, if a viewer, having been exposed to this work in a gallery, with the corresponding guarantee of relevance, in fact finds nothing much to connect it to beyond the proper functioning of a light switch, then cognitive effects will also be low, and their expectations of relevance (the trade off between effects and effort), which are raised by the presentation of the work in an art setting (see $\$ 2$ ) will not be met, and that viewer will leave unsatisfied. If, worse, the viewer sees this work and invests additional cognitive effort, perhaps in the process dredging up remembered ideas about minimalism and conceptual art, and still doesn't get much in the way of worthwhile cognitive effects in return, she might have the sensation of having been made a fool of. This is an unfortunately common response in the face of certain types of modern art. The ostensive presentation of the artwork makes, as we have discussed, an implicit promise of worthwhile cognitive effects (see \$2), and if these are not borne out the sensation is akin to having been lied to. This can in turn create a degree of skepticism towards modern art in general, causing that viewer to doubt whether a modern artist really has anything to 'say' at all. If, on the other hand, a viewer sees this work and has been recently thinking about the changed perceptual states created by small environmental alterations, is habitually interested in thinking about ways to rethink the traditional conventions of gallery display, and happens to have yesterday 
read an article about light travelling through the universe, that person might stand in the room for hours, allowing that sensory experience to connect up with those thoughts, and thinking through Creed's previous endeavours with new eyes. This person will have an entirely different experience of the work. Factors that can affect cognitive effects, such as the frequency and recency of the viewer having entertained particular beliefs, combine to lower processing effort in making rich and rewarding interpretations.

To achieve these effect in audiences, the modern artist must still be highly skilled. Works need to present something that will facilitate such complex interpretations, or else the gallery cannot have an effect on it. Take, for example, Banksy's early work, pieces of street art that often come close to functioning like visual puns. They are pithy, clear and determinate in meaning. As street art, it must offer some relatively easy effects to reward attention, and they do this efficiently. However, questions have been raised about whether it really works when taken off the street and into the province of the artworld proper (Saltz, 2013; Jones, 2013). Because in the more pun-like works there tends to be a single meaning to be found, there will be diminishing returns when investing additional interpretive effort. We suggest that the quiet, revelatory atmosphere of a modern gallery can only work if it is possible to entertain multiple, ambiguous and/or unresolved meanings; if one interpretation straightforwardly beats the rest then it will resolve into the relevant implicature, and this profound and ambiguous experience is lost. A classic early Banksy piece may therefore seem worse off due to its being in a situation that promotes the style of depth and interrogation to which it is not suited. The viewer is primed and ready to invest a large amount of effort, and on finding that the effects are fewer and less complex than expected, that viewer will likely be disappointed.

We can understand something about the current form of the gallery with these effects in mind. The gallery has changed a lot, from the days of salon-style shows to the more contemporary white cube style. Art undergraduates are told repeatedly that the gallery space must be utterly clean. We suggest that because so much of the work of indicating what is and is not art is done by the gallery framing itself, it makes sense that we go on to treat anything that is placed within the gallery walls as intentional—even when it is not intended to be; for example, on the occasion when teenager left a pair of glasses on the floor of the San Francisco Museum of Modern Art, and they were assumed by many viewers to be a work of modern art (Hunt, 2016). 
Of course, non-white-cube venues are still used — venues such as warehouses or old car parks can be widely seen functioning as very effective contemporary art spaces. An institution's 'hushed tones' can be exported to works that exist in all manner of public spaces by virtue of explicit or implicit sanctioning of a work. By promotion within the sphere of influence of the gallery, or the art-world culture more generally, certain artists or their works can be approached as within the realms of that culture, and the extra investiture of effort can still occur. In Spiral Jetty by Robert Smithson (1970), the journey to see the artwork is in itself subjected to 'hushed tones', and is treated as a pilgrimage (The Mythic Scale of History and Labor at Spiral Jetty, n.d.). In these cases, the artwork is more likely to be large or incongruous enough to make its intentionality self-evident, and the boundary of the gallery framing is not so strictly enforced (a pair of glasses in the corner of Anish Kapoor's installation at the old fruit market in Brighton (2009) would probably be more likely to be seen as lost property). For the full emphatic effect to work, a significant art-world framing is necessary, in the form of advertising, literature, an artist's reputation, or evident hallmarks of artworld framing in the characteristics of the work itself. Without these, it might be possible to encounter an artwork simply as a puzzling object, without the emphatic effect being able to take hold. With this in place, we also note that the particulars of the space are also read as intentional—a decision by the art world to branch out and respond to, say, industrial spaces, public places, or nature.

\section{Conclusion}

We have presented a cognitivist account of viewer experiences of contemporary Western fine art, making a clear link between cognitive approaches to human communication, and several prominent lines of thought in art theory. We hope that in so doing we have cast some light on the fine art world, and in particular, on the way that art is viewed and experienced by audiences. Viewers of works of art reach remarkably complex and nuanced interpretations without any real expectation of settling on one that is in some way 'correct'. The cultural framing effects that we have pointed to go some way towards explaining what it is that makes such interpretations both available and tolerable to the viewer.

The core insights here could be applied in many realms. The world of contemporary Western fine art is so rarefied and, for many outsiders, mysterious, that it makes a very intriguing case for analysis, but we see the potential for an application of similar ideas in many associated realms of human creative endeavour, such as humour, science, religion, and many others. More generally we have aimed to situate the Western 
fine art tradition in the broader context of human behaviour, as a phenomenon that is a consequence of both human biological heritage—in particular the cognitive processes involved in communication—and of cultural norms, practices and institutions. A cognitivist view of communication, such as Relevance Theory, provides a way to link individual interpretive experience withe the workings of large social structures of institutions, and as such has much to offer as a framework for exploring and explaining many aspects of human behaviour. 


\section{Bibliography}

Adorno, T. W. (1997). Aesthetic Theory. A\&C Black. (Original work published 1970)

Barthes, R. (1978). Death of the Author. In Image-Music-Text (pp. 143-148). Farrar, Straus and Giroux.

Brabanter, P. D. (2010). Uttering Sentences Made Up of Words and Gestures. In Explicit Communication (pp. 199-216). Palgrave Macmillan, London. https://doi.org/10.1057/9780230292352_13

Bullot, N. J., \& Reber, R. (2013). The artful mind meets art history: Toward a psycho-historical framework for the science of art appreciation. Behavioral and Brain Sciences, 36(2), 123-137. https://doi.org/ 10.1017/S0140525X12000489

Carston, C. (2002). Thoughts and Utterances: The Pragmatics of Explicit Communication. Oxford, U.K. ; Malden, Mass: John Wiley \& Sons.

Carston, R. (2008). Relevance Theory and the Saying/Implicating Distinction. In The Handbook of Pragmatics (pp. 633-656). Blackwell Publishing Ltd. https://doi.org/10.1002/9780470756959.ch28

Clark, B. (2013). Relevance theory. Cambridge: Cambridge University Press.

Collins, G. C., \& Sandell, R. (1987). Women’s Achievements in Art: An Issues Approach for the Classroom. Art Education, 40(3), 12-21. https://doi.org/10.1080/00043125.1987.11652013

Creed, M. (2000). The Lights Going On and Off.

Danto, A. (1964). The Artworld. Journal of Philosophy, 61(19), 571-584.

Dickie, G. (1971). Aesthetics: an introduction. Pegasus.

Duchamp, M. (1914). Bottle Rack.

Duchamp, M. (1917). Fountain.

Enright, A. (2017, September 21). Diary. London Review of Books, pp. 33-35.

Farrell, J. (2017). The Varieties of Authorial Intention: Literary Theory Beyond the Intentional Fallacy (1st ed. 2017 edition). New York, NY: Palgrave Macmillan.

Fodor, J. A. (2012). Déjà vu all Over Again. In rk Rollins (Ed.), Danto and his Critics (pp. 55-68). WileyBlackwell. https://doi.org/10.1002/9781118253045.ch4

Garber, E. (1992). Feminism, Aesthetics, and Art Education. Studies in Art Education, 33(4), 210-225. https://doi.org/10.1080/00393541.1992.11651877

Gell, A. (1996). Vogel's Net: Traps as Artworks and Artworks as Traps. Journal of Material Culture, 1(1), 15-38. https://doi.org/10.1177/135918359600100102 
Graham-Dixon, A. (2017, February 14). This Is the Modern World. Art of France. London: BBC. Retrieved from http://www.bbc.co.uk/programmes/b08f1bw0

Grice, H. P. (1957). Meaning. The Philosophical Review, 66(3), 377-388.Grice, H. P. (1989). Studies in the Way of Words. Harvard University Press.

Higgs, J. (2015, September 8). Was Marcel Duchamp’s 'Fountain’ actually created by a long-forgotten pioneering feminist? The Independent. Retrieved from http://www.independent.co.uk/arts-entertainment/art/features/was-marcel-duchamps-fountain-actually-created-by-a-long-forgotten-pioneering-feminist-10491953.html

Hunt, E. (2016, May 27). Pair of glasses left on US gallery floor mistaken for art. The Guardian. Retrieved from http://www.theguardian.com/us-news/2016/may/27/pair-of-glasses-left-on-us-galleryfloor-mistaken-for-art

Jackson, R. (2016). The Pragmatics of Repetition, Emphasis and Intensification. University of Salford.

Jones, J. (2013, February 19). Banksy: overrated purveyor of art-lite. Retrieved 6 March 2018, from http:// www.theguardian.com/artanddesign/jonathanjonesblog/2013/feb/19/banksy-overrated-art

Kapoor, A. (2009). The Dismemberment of Jeanne D'Arc.

Kendon, A. (2004). Gesture: Visible Action as Utterance. Cambridge ; New York: Cambridge University Press.

Levinson, J. (1979). Defining Art Historically. British Journal of Aesthetics, 19(3), 21-33.

Levinson, J. (1989). Refining Art Historically. The Journal of Aesthetics and Art Criticism, 47(1), 21-33. https://doi.org/10.2307/431990

McNeill, D. (2005). Gesture and Thought (1 edition). Chicago, Ill.: University of Chicago Press.

Parker, R. (2010). The Subversive Stitch: Embroidery and the Making of the Feminine. I.B.Tauris.

Recanati, F. (2001) What is Said. Synthese 128 (1/2): 75-91.

Saltz, J. (2013, October 21). Watch Jerry Saltz Hold an Impromptu Art Class at Banksy's Latest. Retrieved 6 March 2018, from http://www.vulture.com/2013/10/jerry-saltz-banksy-seminar.html Scott, K., \& Jackson, R. (2017, September). When EVERYTHING STANDS OUT, Nothing Does: Typography, Expectations and Procedures. Presented at Beyond Meaning, Athens.

Scott-Phillips, T. (2014). Speaking Our Minds: Why buman communication is different, and how language evolved to make it special (2015 edition). Houndmills, Basingstoke, Hampshire ; New York, NY: Palgrave. 
Scott-Phillips, T. C. (2015). WHAT IS ART? A PRAGMATIC PERSPECTIVE. Think, 14(40), 87-91. https://doi.org/10.1017/S1477175615000093

Searle, J. R. (1969). Speech Acts: An essay in the philosophy of language. Cambridge: Cambridge

University Press.

Smithson, R. (1970). Spiral Jetty.

Sperber, D. (2010). The Guru Effect. Review of Philosophy and Psychology, 1(4), 583-592. https://doi.org/ $10.1007 / \mathrm{s} 13164-010-0025-0$

Sperber, D., \& Wilson, D. (1995). Relevance: Communication and Cognition. Wiley.

Sperber, D., \& Wilson, D. (2015). Beyond Speaker's Meaning. Croatian Journal of Pbilosophy, 15(2), 117-149.

The Mythic Scale of History and Labor at Spiral Jetty. (n.d.). Retrieved 17 September 2017, from https:// hyperallergic.com/200358/the-mythic-scale-of-history-and-labor-at-spiral-jetty/

Weiwei, A. (1995). Dropping a Hang Dynasty Urn.

Werth, P. (2016). Focus, Coherence and Emphasis. Routledge.

Wharton, T. (2009). Pragmatics and Non-Verbal Communication (1 edition). Cambridge, UK; New York: Cambridge University Press.

Wharton, T. (2016). Paralanguage. In A. Barron, G. Steen, \& G. Yueguo (Eds.), The Routledge Handbook of Pragmatics (pp. 69-75). London: Routledge. Retrieved from http://eprints.brighton.ac.uk/15447/

Wilson, D. (2011). Relevance and the interpretation of literary works. Observing Linguistic Phenomena: A Festscbrift for Seiji Uchida, 3-19.

Wilson, D., \& Sperber, D. (1986). On Defining Relevance. In Philosophical Grounds of Rationality (pp. 243258). Oxford University Press.

Wilson, D., \& Sperber, D. (2004). Relevance Theory. In The Handbook of Pragmatics (pp. 607-632). Oxford: Blackwell.

Wilson, D., \& Sperber, D. (2012). Meaning and Relevance. Cambridge ; New York: Cambridge University Press. 